\title{
Palestinian Refugees and Mediated Connections to Palestine ${ }^{1}$
}

\author{
MAY FARAH, American University of Beirut
}

\section{ABSTRACT}

This article presents a description and analysis of young Palestinian refugees media use in the context of a newly globalized media age. Refugees, like diasporic populations everywhere, live in a world marked by de-territorialization and reterritorialization, where such populations often come to think of themselves as part of a national community via mediated representations. The new media - satellite television and the internet - has helped shape their understanding and connection to Palestine and other Palestinians. For the young refugees living in refugee camps in Beirut, maintaining a strong connection to Palestine and a Palestinian community motivates their media access and use, which is tied to their desire to return to Palestine, even one made up of a geographically different area in the Occupied Palestinian Territories (OPTs). Indeed, it is via media that the refugees have come to learn of the OPTs, where they hope to 'return' to live in a recognized Palestinian state.

\section{KEYWORDS}

Palestinian refugees; media; the Occupied Territories; mediated connections

\footnotetext{
${ }^{1}$ This article is based on material from a larger research project, some of which appears in a different form in Farah, May. (2014), 'Mediating Palestine', in M. Shumow, (ed.), Mediated Communities: Civic Voices, Empowerment and Belonging in the Digital Age. New York, NY: Peter Lang
} 


\section{Introduction}

Palestinian refugees in Lebanon have always mediated Palestine. From the first refugees who arrived in 1948 to today's youth, the third generation of refugees ${ }^{2}$ now living in camps in Lebanon, the media have proffered a means to stay informed about current events and a vehicle through which to connect to their homeland. What distinguishes the more recent media environment, however, is both the plethora of media available and, for a growing number of younger refugees, what accessing the different media has meant to their understanding and connection to Palestine.

Young Palestinian refugees in Lebanon have never experienced their homeland firsthand; their understanding and knowledge of Palestine has been available only through second-hand accounts, both stories told by their grandparents and elder neighbors, or what Young calls "received memory" $(1997,21)^{3}$, and through the media. Unlike their parents and grandparents whose media choices were limited, these young adults have come of age in a time of transnational media that permeates virtually every corner of the globe, and brings images and sounds of faraway places and peoples to equally faraway places and peoples. With the media reaching virtually all those places, "moving images meet deterritorialized viewers" (Appadurai 1996, 4). In other words, because these refugees cannot travel to Palestine, it is the media that provide them with information and images of events and everyday life in Palestine. Their experience of growing up de-territorialized from their homeland and reterritorialized in new places, and in a world of globalization and globalized media, means these young refugees access stories and whatever media is available to them to help understand, remain connected to, and learn of recent events in Palestine.

This article examines how young adult Palestinian refugees in Lebanon rely on media - mostly television and the internet - to not only connect to Palestine and Palestinians living in Palestine, but also to learn about the conditions and situation inside, to see photos of Palestine today, and stay-up-to date with real-time accounts from both the mainstream media and alternative sources. Thus, one question that I address here concerns the role the contemporary media play "in the construction of our sense of ourselves" as members of communities (Morley and Robins 1995, 69). I argue that it is through media that young Palestinians have learned of, and in most cases come to accept, the Occupied Palestinian Territories (OPTs) as the potential future independent Palestinian state (if they are granted the right of return), their community. As I elaborate below, and as I learned from my interviews with young Palestinian refugees living in camps in Beirut, the media allow them daily access to news and other programming and content on Palestine. They access websites that provide more elaborate reports and images of their homeland. Their media use is dictated by an interest in Palestine foremost, and their main concern is keeping up-to-date with news and events that are of a direct concern to their lives.

\footnotetext{
${ }^{2}$ I use the term refugees here, and not diaspora, as the population labels itself as refugee for political (right of return) and economic (UN assistance) reasons.

${ }^{3}$ Alison Landsberg suggests the term "prosthetic memory" to put forth the idea of how people who have not directly experienced historical events can nevertheless assimilate them as personal. Similarly, Marianne Hirsch calls memories of traumatic events that mark those that didn't experience them post memory. Space limitations prevent further elaboration here; see Young 1997; Landsberg 1995; and Hirsch 2002, for a rich engagement of these notions.
} 
Moreover, while the majority of Palestinians that fled to Lebanon, who are now Palestinian refugees in Lebanon, came from parts of Palestine that are now Israel, the return to their homeland would entail a return to a future Palestinian state, right now the OPTs. The young refugees recognize this. When they speak of Palestine in their conversations, they are, as I understand it - and as I use Palestine here - referring to what are now the OPTs. Although there were two or three young refugees who said they would reject any return that would not entail a return to their village of origin, most refugees understand and accept that their villages (inside Israel) will not be returned. I will return to a more detailed discussion of this below.

I begin first by briefly outlining the methods employed in order to address the central research questions here, that is what media do young refugees access, why, and what have they gained by accessing this media. This is followed by an examination of how scholars have theorized the media's role in contributing to a sense of self and community, and an historical account of media availability and access since the first refugees arrived in Lebanon in 1948. Finally, I address the more recent media environment in which today's young refugees live. Based on my interviews with this population, I then discuss what role the media play in these young refugees lives, which is followed by a few concluding remarks.

\section{Methods}

The overall approach of this study is ethnographic, complimented by structured qualitative collection and analysis techniques. My approaches for data collection and analysis were influenced by both the research questions and the contexts in which the research was conducted, as discussed below.

Jensen (1998) proposes two types of research methodologies that can be employed in this area. A multi-method, ethnographic approach can investigate how specific audiences engage "several different media and genres as integral elements of their everyday practices;" while reception methodologies "can examine how several different audience groups interpret, experience, and use a specific medium or genre in context," such as considering a variation of news forms and cultural contexts in which they are consumed $(1998,12)$. In other words, reception analysis allows the exploration of "how audiences make sense of the media and make use of them as resources in everyday life" (Jensen, 1998, 13).

I chose not to investigate one particular genre or medium, but the different media Palestinian youth refugees' use, and how their choices often serve to compliment or reinforce their understanding of and connection to Palestine. I was interested in examining how and why young adults access the various media available, and how their media use potentially serves to complement their inherited stories and memories. ${ }^{4}$ More specifically, a number of research questions guided my observations and interviews: What relationship did these refugees have to media?;

\footnotetext{
${ }^{4}$ Like Young's (1997) "received memory," that speaks of the relationship between the story or memory being passed down and the those receiving the story, the Palestinian refugees' inherited memories affect their own accounts of Palestine, particularly as these are often impacted by the stories and images they access via media.
} 
how did they use it?; how often?; what and how did the media content represent to their imaginations of Palestine? I began with observing media use among refugees, and participated in watching and accessing online content with them, which was followed by interviews. This strategy allowed me to better understand the context in which these youth were exposed to media, which, as Patton notes, is essential to a "holistic experience" $(2002,262)$.

For the present research, I conducted in-depth interviews with over 50 young adults (ages 18 to 25) from three camps in Beirut (Burj Barajneh, Shatila, and Mar Elias) during several months over a period of two years (2008 to 2009), and then more recently in 2011 and 2012. Why young adults? In addition to their inherited accounts of Palestine, this generation has had access to a highly rich media environment particularly the explosion of satellite television, the growth of Arab and pan-Arab media and the increasing availability of the internet - as potential sources to understand and connect to Palestine. Their understanding and knowledge of Palestine, therefore, comes from family stories, but increasingly from mediated constructions and representations.

When I arrived at the Burj al-Brajneh camp, I had obtained the name of a contact person, Nada (not her real name), a working mother of two who spoke English well, and who, in the past, had coordinated requests from a number of doctoral students doing research in the camps. Nada's two children were 18 and 16, and they allowed me to observe them as they used media alone or with friends or family members. Over the next week, Nada took me on visits with her to neighboring homes where I met a number of youth informally, and was given the opportunity to make observations. It was through participating in their media use and my observations that I recognized certain issues, for example their focus on news programming, the stations they most often tuned into, what internet sites they accessed, and the related conversations they had with family members, which I made note of in order to pursue in my interviews.

One week later, and with Nada's help, I secured interviews with numerous young adults. Nada also introduced me to an NGO working in the Shatila and Mar Elias camps, the Joint Christian Committee for Social Services, who helped me secure participants. Going through such organizations within the two camps and asking for their assistance in locating individuals who fit my research participant profile was a more productive way to secure participants.

Moreover, I could get more trust and hence deeper conversations as a result of being "vetted" by a known and respected fellow refugee. Using convenience sampling can be justified in a number of situations. As Jensen notes: "a well-documented convenience sample can generate both valid and reliable insight into a setting or event". He continues: "... given the notorious difficulty of gaining entry to certain social arenas, convenience in the sense of physical and social accessibility is a legitimate consideration" $(2002,239)$.

In each location, I carried out in-depth interviews using a "guided" interview format (Rubin and Rubin 1995) that incorporated a series of open-ended questions consistent among all interviews, and that also provided opportunities for participants to expand on their responses but ensured ample structure to facilitate comparisons during data 
analysis ${ }^{5}$. In some cases, especially with participants who appeared to be more reluctant or shy, the questions were not administered in the same order as with other participants.

The interviews took place in participants' homes and camp cultural centers. Often times, siblings, parents, or friends were also present, but did not participate in the interviews. I allowed the participants to choose the interview setting to ensure their comfort. Each interview lasted between 45 minutes and one hour.

The questions focused upon several areas, such as: media availability and use, frequency, programming and station preference, observations on media content, understandings of Palestine, sources of knowledge of Palestine, how they imagine Palestine, what it means to be Palestinian and what role the media played in this, if any, and their feelings on the right of return.

The interviews were conducted in Arabic, although some respondents did speak English and answered some questions in English. However, because Arabic is their native tongue, and because I wanted them to feel comfortable and confident expressing themselves, I purposely posed all questions and made any comments in Arabic. Although my Arabic is fluent, there are some words and phrases used in the Palestinian dialect that were unfamiliar to me. As such, I had assistance with the transcription from a native Palestinian speaker to ensure that I accurately transcribed the interview.

I analyzed the data from the interviews with refugees by first looking at each person as a "case study" and then looking for similarities in answers. I looked for noticeable patterns to see what story emerged overall. Jensen notes that, "It is the very occurrence of a particular theme or frame in a context of communication which is of primary interest to qualitative research. Such categorizations of data, in turn, can support inferences concerning, for example, the selective reception and reconstruction of news items by different audience groups" $(2002,247)$.

As a final and important note, all of the names of participants have been changed to protect their identities.

Before elaborating my findings, I want to first briefly examine how scholars have theorized the media's role in contributing to a sense of self and community, and then provide a brief landscape of media availability, from the time of the Nakba ${ }^{6}$ generation to the present. I do this in order to demonstrate the different media available to the different generations, and elaborate why this generation's media access has provided a potentially greater connection to Palestine, despite the lack of first-hand experience and personal memories, and allowed them to imagine themselves as part of Palestinian area different than their parents and grandparents.

\footnotetext{
${ }^{5}$ I tried to include a similar format of questions in each interview, although the flow differed depending on the youth's responses.

${ }^{6}$ Arabic for catastrophe, the term Palestinians use to refer to the 1948 expulsion from their homes upon the creation of the state of Israel. A number of scholars (for example, Joseph Massad and Lila AbuLughod) argue that the nakba did not end in 1948 but is ongoing.
} 


\section{History of Media Available to Refugees}

For over two decades, theorists have been exploring the fundamental role the contemporary media play in circulating images and narratives that foster and sustain acts of imagination key to the constitution and shaping of national identification, the links between identity and communication flows, and how audiences draw on media to make sense of their everyday lives (c.f. Appadurai 1991; Kelly 2004; Morley and Robins 1995; Naficy 1993; and Shohat and Stam 1994). Ella Shohat and Robert Stam link media to the "very core of identity production." In today's world characterized by "the global circulation of images and sounds, goods and people," they argue, "media spectatorship impacts complexly on .... communal belonging." Thus, through media, all audiences are exposed to global images, narratives, events, and traditions, demonstrating how the media have facilitated "an engagement with distant people... [and] 'deterritorialized' the process of imaginary communities" (1994, 6-7). Via media, refugees can witness traditions and communities of homelands that they have never experienced directly.

As Jennifer Kelly notes, it is a mediated culture which young adults "draw on to make sense and produce knowledge of their everyday experiences" $(2004,194)$. According to her, "meaning is produced through regimes of representation mediated by magazines, music, and television music videos." Media representations thus enable us "to code and construct common understandings" (Kelly, 2004, 158). Being deterritorialized from the country that refugees have grown up referring to as the homeland, has meant that common symbols and representations have been constructed and imagined with the aid of the media (and recounted stories) and serve to bind them to each other, and to Palestine.

The media broadcast/transmit messages that travel to the refugees- wherever they may be - rather than the refugees "having to travel to them" (Gupta and Ferguson 1997, 9). People, particularly deterritorialized populations, are imagined as belonging to more than one place, and the media reach all those places, including the refugee camps of Lebanon. As I elaborate further below, refugees learn about, come to understand, and "connect with their cultural group through media contents" (Jamal 2007, 560).

When the Nakba generation arrived in Lebanon, television broadcasting was still a few years away. However, a number of well-established and respected newspapers were already available, and numerous others gradually became available as well, along with one radio station, Radio Levant (Ash-Sharq). ${ }^{7}$ Dajani notes that "The 'rush' to publish newspapers in the early 1950s was a natural result of the great economic and political changes that Lebanon and the area were facing, changes that made Lebanon prosper as a leading center of finance, business and diplomacy in the Middle East" (1992, 35). Thus, the first generation of refugees in Lebanon had access to both local and regional newspapers, including the Lebanese dailies an-Nahar, AdDiyar, and Al-Ahrar, and the regional Al-Hayat - as sources of information. Although Radio Levant began broadcasting in Lebanon in 1938, it was not until the late 1950s, and in an increasingly polarized political situation, that three newer radio stations were established, "each propagating ideas and news of its own faction" (Dajani 1992,

\footnotetext{
${ }^{7}$ Radio Levant became Radio Lebanon in 1975.
} 
80). As concerns the Palestinians, however, most radio broadcasting that focused on news was concerned with local news in Lebanon and the growing discontent and hostilities among Lebanon's different sects, although there was certainly news of Arab efforts and plans against the Israeli enemy. However, refugees who wanted detailed accounts and information of events inside Palestine and Israel were more likely to find such content - limited at it was - in the various newspapers that covered both local and pan-Arab news.

By the late 1950s, television broadcasting also began in Lebanon, but, like radio before it, government regulations of the newly developing industry were not concerned with promoting education and awareness, but rather at "allowing officials and the ruling political bosses to exploit this medium for their own political goals" (Dajani 1992, 92). Before Lebanon's civil war (1975-1990), there were only two television stations broadcasting in Lebanon: CLT and Tele Orient ${ }^{8}$, both offering Arabic and foreign programming. During the war, however, and with the weakening of the central government, the political factions hijacked the airwaves with each party launching its own broadcasting station. In subsequent years, the number of stations in Lebanon multiplied and by the end of the war, Lebanon had over 45 television stations and 185 radio stations, most operating illegally and most broadcasting poor quality foreign fare or news programming that favored one faction over the others. For the 1948 and 1967 refugees, this meant coverage that was both favorable (and therefore detailed) and unfavorable, depending on which faction-sponsored station was broadcasting, and whether it was aligned with the Palestinian cause.

In the early post-war years, the government took steps to finally regulate the broadcasting industry through the 1994 Audiovisual Media Law. A number of stations without licenses were shut down and only seven were granted permission to legally broadcast news information. ${ }^{9}$

Although the next generation of refugees inside Lebanon lived during a period of substantially greater media availability - dozens of daily, weekly and monthly newspapers and news-magazines, a plethora of radio stations, and an increasing number of television stations each with its own political agenda - again much of the content was either locally produced (and therefore spoke to national concerns) or foreign fare (American and French programming). There is little evidence of detailed coverage of specific concerns to Palestinians - such as non-political news of daily life in the OPTs. Many parents and grandparents of the young generation I interviewed complained to me about the insufficient or limited Palestinian-related news available to them previously: it generally focused on criticism of the PLO's role in Lebanon or of Arab-Israeli contentions.

\footnotetext{
${ }^{8}$ In 1977, CLT and Tele Orient merged to become Tele Liban, which still operates today, and is the only public station - its operations are overseen by a board of 12 members, 6 from the government and 6 from the original two companies - among a multiplicity of private-owned stations.

9 The seven - Tele Liban, LBC, MTV, Future, NBN, Al Manar and NTV - are aligned with the different sectarian factions, with the exception of Tele-Liban which is half private and half government owned. In the mid-2000s, another station, OTV, also aligned with a political faction, was granted a license, as was Future News, an off-shoot of Future TV dedicated solely to news. For more information, see http://www.pressreference.com/Ky-Ma/Lebanon. html\#ixzz1JhPSn1Qw
} 


\section{Media Explosion in the Arab World}

Since the early 1990s, aided by advancements in satellite technology, the number of television stations has skyrocketed. They now run into the hundreds for those with satellite access, which has become the norm in the Arab world (Sakr, 2007, 1) in general, and in Lebanon in particular, the camps included ${ }^{10}$. With the advent of Arab owned satellite stations (MBC, LBC Sat, Dubai Media Incorporated) and 24-hour pan-Arab news channels (Al Jazeera and Al Arabiya) in the late 1990s and early 2000s, the media landscape in the Arab world radically changed, providing newer generations with access to stations and content from virtually every corner of the world.

The young generation of Palestinian refugees in Beirut, therefore, has grown up in an era characterized not just by greater and more diverse sources of news and information on Palestine, but also content that is produced and disseminated by Arabowned stations. In addition to a greater quantity of high quality Arab-produced entertainment programming (as well as foreign - mostly American - content), around the clock news programming is produced by Arabs and aimed at a pan-Arab audience, and "the Israeli-Palestinian conflict has been a constant theme in Arab reporting" (Kraidy and Khalil 2009, 78). Thus, for example, in Lebanon, in addition to the six major private broadcasters and several smaller stations, viewers can access television networks from across Europe, Asia, and the Arab World, including one or two Palestinian television stations. And while governments across the region attempt to control the new media, their abilities to do so are often eroded by even newer technologies. The result - in Lebanon, at least - has been a commonly unfettered access to the newly available hundreds of channels.

This new media environment, which also includes growing access to the internet, has allowed communities the ability to feel that they are linked and belong, and, at the same time, they enable audiences to maintain contact with the past "through the circulation of place-based nostalgia and memory" (Couldry and McCarthy 2004, 3). Moreover media connect sites to other "geographically distant but communicationally present places" (Morley 2000, 87).

Thus, the Palestinian refugees in Lebanon now have access to the internet, and government-run stations and private stations from every country in the Arab world and beyond. The new "mediascape," to borrow Appadurai's (1990) term, has also paved the way for new research possibilities on mediated connections to people and places.

Such research is unavailable for previous generations of Palestinian refugees in Lebanon, largely because, as noted, media availability before the last couple of decades was limited. As a result, beyond describing this limited media availability, it is difficult to assess the role of the media that was accessible before the late 1990s among the previous generations, and whether the media facilitated attachments to and imaginings of Palestine and connections to Palestinians inside Palestine. It might be

\footnotetext{
${ }^{10}$ In many cases, particularly in the camps but also in most neighborhoods across the country, cable is illegally accessed. For anywhere from $\$ 10$ to $\$ 25$ per month, hundreds of channels from a number of satellites are made available. Many homes share one connection by using splinters with cables that extend from one central location to dozens of homes surrounding it.
} 
safe to predict, however, that in the absence of satellite broadcasting, 24-hour panArab news stations, the internet, and other new media now available, the media's impact was limited at best.

\section{The Young Refugees' Turn to Media}

For the young adult refugee population that has grown up in the camps, their only sources of knowledge about their homeland have been stories and the media, in other words, second-hand accounts; as such, they have only been able to imagine Palestine, not experience it directly. Through stories recounted by older generations, then, and increasingly through the media, these refugees have learned the details of their lost homeland and have stayed abreast of current news and events. It is this determination to stay connected and maintain this active remembrance that have helped refugees preserve a dynamic sense of their history and their present.

The Nakba generation, now elderly, knew Palestine firsthand and was "able to vividly juxtapose the past and the present." And, although stories of "life in Palestine evoke a nostalgic longing for a past that is irretrievable" (Peteet 1995, 180), this older generation reinforced a strong sense of who they are and where they came from by repeatedly telling and passing down stories of the Nakba, of their lost villages and homes, by keeping alive their "memory of a common past" (Morley and Robins 1995, 46). As Sayigh notes, "Re-creating Palestine through memory was not only a natural reaction to forcible separation, it was also a way - the only way - of passing on to children the homes that were their inheritance..." $(1979,3)$. In the camps, then, it is the repetition of these stories, or as Feldman notes, the "refrain" repeated among the refugee population that helps to "reproduce home," even when their homeland, their territory is beyond reach. "It can help reintroduce a kind of security, even when chaos is all around. To a certain degree, a refrain is experience. That is, it is through these repetitions, incantations, circulations that people experience the security of home" (2006, 17).

In so far as these refugees are surrounded by older generations of Palestinian refugees, they are exposed to constant and prolonged stories of lost homes and the homeland. These stories remind the young adults of their Palestinian origins and reinforce their connection to and understanding of Palestine. Many recounted how, from the time they were young, elder family members or neighbors would talk in detail of their land and villages, of what Palestinian life was like, and of their tragic loss. Twenty-year-old Mohamad, who was born and raised in the Shatila camp, explains that besides speaking directly to a parent or grandparent about Palestine, the family (and often neighbors) "would sit around in large circles and the older generation would take turns sharing stories." Ahmad, 23, from the Mar Elias camp, shares a similar opinion:

From the beginning, a child first learns the map of Palestine, and its flag and the right of return and so on. So the child wakes up about his/her country and starts asking the older generation who actually lived in Palestine. We start asking questions about this town and that, what they are famous for and where they got their names from and so on. 
These young adults, then, have grown up learning the vivid details of their homeland. As such, a right to return to live in Palestine, among fellow Palestinians, and as legitimate members of a recognized state is their greatest dream.

This generation has also grown up with a plethora of television channels, particularly pan-Arab television, and the internet that were not available to older generations. The explosion of new media has helped young Palestinians access more up-to-date and detailed accounts and images of Palestine, accounts and images of day-to-day life as Palestinians in Palestine are experiencing it. These media have served to "play a powerful role in the construction of collective memories and identities" (Morley and Robins 1995, 91). A global reliance on television as a cultural resource for a growing number of people to "supply their needs, both for information and entertainment" has been well supported (Morley and Robins 1995, 68-9).

For many, the media have been an especially useful source with which to complement the stories they have grown up listening to and present a more complete picture of current events in Palestine. As 22-year-old Maher said, "The information I have on Palestine is definitely more than what my grandparents have because they only have their memories and experiences. I have been told those stories, plus I have television, which occasionally I watch, and internet which I use almost daily." For Maher, the internet allows him to chat regularly with friends who live in the OPTs whom he met online. "They give me the whole picture about what is going on," he says.

When refugees talk about watching television, they are generally referring to the panArab news stations, such as Al Jazeera, which, for the first time, provides them with round the clock coverage of current news stories and events. And, since the Palestinian situation remains a topical issue, content on various aspects of Palestine the ongoing conflict with Israel, the condition of life in the OPTs, political negotiations on the right of return - are regularly and widely available, and from an Arab perspective.

Mohamad, who is 24 and lives in the Burj al Barajneh camps, said it is regularly watching news on Al Jazeera that allows him to remain connected to Palestine, and imagine what "my country is like today." During our entire conversation, he kept one eye on the television that was in the corner of the room and tuned into Al Jazeera. When I noticed him glancing at the TV, he told me he just wanted to make sure he was not missing any breaking news. Like Mohamad, Adel, who is a 21-year-old university student, is an avid news watcher, making sure to tune into three channels (Al Jazeera, Al Arabiya, and the Lebanese channel Al Manar) for a few hours every night before going to bed. For news on Palestine, he favors Al Jazeera because he says it offers the best coverage of the Palestinian struggle.

A point often repeated to me during many of my interviews with young refugees was not only was the coverage they watched or accessed online presented in Arabic, it was generally produced by Arabs, written by Arabs, and with an Arab audience in mind. In other words, the Western bias was mostly absent. 
Transnational media, satellite television and the internet are important sites for young refugees as they project "negative images of Israel to the region" and "regularly include in their evening broadcasts reports on Israeli settlement construction, home demolition, and open conflict with Palestinian Arabs" (Alterman 1988, 57). In other words, while the stories told were of the past, the mediated accounts tell of the present situation.

These broadcasts have served to significantly reconfigure the current generation's sense "of space and place" (Morley and Robins 1995, 1). Today, it is not only the content gained from watching the evening news broadcasts or other information programs that is important, but equally significant is "the fact of watching, and engaging in a joint ritual with millions of others" (Morley and Robins 1995, 68). For example, Palestinian refugees in the camps who tune in to Al Jazeera for their nightly news programs are aware that millions of other Palestinians - in Lebanon and elsewhere - are witnessing the same news. "New technology allows Arabs across the region and around the world to read, see, and hear the same information at the same time to a degree that is unprecedented" (Alterman 1998, xii). This translates into feelings of shared experiences, or, as Anderson notes, it allows them to feel part of an 'imagined community' (1991); the Palestinian refugees in Lebanon feel more connected to fellow Palestinians in the OPTs since they feel they are able to witness their experiences of life, even though they recognize that the OPTs and Lebanon are very different. Faten, a young refugee from the Shatila camp, told me: "Every day I watch the news and see what Palestinians in the West Bank and Gaza are living through. I feel more connected to them because we are living through some tough times here too. It also makes me feel closer, like I know them personally."

This, for Anderson (1991), constituted an 'imagined community': a connection among all members, each of whom may never know all or even most of the other members, yet is related to them through a shared culture, history, and kinship. It is this, and the belief of these members in these connections, that creates a national community. Thus, the exiled population who are no longer - and never were physically connected to the nation nevertheless imagine themselves as connected to and part of a national community. While for Anderson, an imagined community was possible by print media, I argue that modern forms of media (read television and the internet) aid displaced populations, such as refugees, to remain connected to and part of the imagined community.

For Morley and Robins, it is the new broadcasting technologies that play a "fundamental role in promoting national unity at a symbolic level, linking individuals and their families to the centres of national life, offering the audience an image of itself and of the nation as a knowable community, a wider, public world beyond the routines of a narrow existence" [sic] $(1995,66)$. Broadcasts of events in the OPTs allow refugees to remain connected to and informed about what is happening to their homeland, a place that they hope to be part of when the right of return is granted ${ }^{11}$.

Through the newly available media, places of Palestine now come to the camps and provide refugees with the opportunity "to luxuriate in the landscapes of their lost

\footnotetext{
${ }^{11}$ Interestingly, the young refugees in the camps all spoke of "when" in discussing the right of return. No one spoke of "if."
} 
homeland, to bathe in the sounds of their childhood language" (Shohat and Stam 1994, 354). As I discovered through my observations and interviews, this new media - satellite television and the internet - was a main source for information and images of the OPTs and any events concerning Palestinians. "12 "All these new stations," Salim from the Mar Elias camp said, referring to Al Jazeera and Al Arabiya, "and all the websites we can access online, they all give us more information about every aspect of life in Palestine. We no longer have to rely on the limited and generally biased coverage of the foreign channels." Another refugee, 25-year-old Ahmad, added: "We now have access to pictures of Palestine, and we can see the beauty of our country and cities. My parents, on the other hand, did not have enough information to see the country they came from. They just heard stories about it and about its beauty through word of mouth." Echoing what many young refugees told me, May, also 25, believes that her generation's access to information about Palestine has definitely increased. "The internet does have an advantage in that we now have better communication with friends within Palestine," she said, highlighting that the internet, besides being a source of information, is also a means of communication with other Palestinians inside the OPTs. Through conversations on various chat sites, these refugees have formed relationships with Palestinians inside the OPTs, exchanged information on their respective living conditions, and received a clearer and more detailed understanding of events happening than from what is available via the news media's coverage.

The media, particularly the internet, has also allowed them to imagine themselves as part of a Palestinian community comprised of a potentially new territorial configuration. Many of the young refugees, although admitting that they dream of returning to their specific towns or villages, which are now inside Israel, also acknowledged that if granted the right of return to the OPTs, they would accept in order to be part of a legitimate and recognized Palestinian nation-state. "We no longer want to be refugees, but live legitimately in a Palestinian state," said Hala, 19. The majority of young refugees I spoke to echoed the same sentiment.

For Huda, who is 25 , the media in general, and television in particular, allow her access to stories about the OPTs. Thus, the media provide a window through which she learns of others and imagines their lives under occupation. And it is that imagination that gives her hope to endure her circumstances in the refugee camp in Lebanon as she witnesses others suffering a similar situation. "I learned about new places, the people there, and even found out I have family in Ramallah, with whom I am now in touch on Facebook," she told me.

Thus, the new media has facilitated the means by which these young refugees have learned of the OPTs, initiated connections with other young Palestinians there, and allowed them to begin to imagine themselves as part of that community.

I want to underscore the importance of the media for this young generation in providing not just a more up-to-date understanding and connection to Palestine, but one that is most often territorially different than the Palestine of their grandparents' stories. To that end, I would argue that the new and globalized media have played a

\footnotetext{
${ }^{12}$ Although radio was mentioned once or twice in passing as a source, newspapers and magazines were hardly ever accessed due to their cost.
} 
role in allowing refugees to connect to and imagine a future Palestinian state that would not encompass their original villages and towns, but only the OPTs. This is a Palestine that does not figure in the accounts of the stories they have been told as the majority of refugees who fled to Lebanon were from parts of Palestine that are now (and likely will continue to be) inside Israel. When refugees now speak of a return, many acknowledge and accept that it will be a return to the OPTs, and it is the media that have played a significant role in allowing them to learn of, imagine and connect to what they hope will be the future homeland. ${ }^{13}$

Thus, the media, or more specifically, satellite television stations and the internet, provide them with the means to remain connected to, understand, and thereby imagine themselves as part of a national (legitimate and formally recognized) Palestinian community in the OPTs.

\section{Conclusions}

While older generations may, as Dorai has demonstrated, rely on personal memories of home (2002), for the young adults these accounts and memories of their grandparents (and, in some cases, parents) are just one source to understand Palestine, and their media use is a means to further compliment and update their knowledge and understanding of and relationship to Palestine. The majority of refugees said they often tune into programming and use the internet to further complement the stories they have been told and access more contemporary accounts of the OPTs.

The refugees rely on media that talk to them of Palestine, including news and cultural programming, to learn about their homeland; this is tied to their imagining themselves as part of a Palestinian community, even if that community is to be located inside the OPTs.

As such, when the refugees speak of their homeland, they are referring to Palestine. However, it is not necessarily the Palestine of their grandparents' generation. In the past, Palestine referred to the territory that existed prior to 1948 (i.e. British Mandate Palestine), a large percentage of which became the state of Israel. This is the Palestine that the Nakba generation was attached to, fled, and recall in their accounts of the homeland. Today, when the young Palestinian refugees I spoke with talk of a return to Palestine, they largely refer to the post-1967 borders that comprise Gaza, the West Bank and parts of East Jerusalem (OPTs). Moreover, the young refugees have no direct recollection of Palestine. Acca (inside Israel) to them is just as imaginary as Ramallah (inside the OPTs). For them a return to their homeland is a return to their country of origin (whatever territorial shape it might take), and where they will be accepted as citizens, as members of a recognized and legitimate state.

As the Arab World continues to experience a changing media landscape, it opens the doors for further research that investigates how media increasingly reach deterritorialized populations like refugees, providing one source for connections to

\footnotetext{
${ }^{13}$ If there is a future Palestinian state, it will constitute those areas that are now the OPTs. Thus, for those refugees hoping for return and even those who desire to remain in Lebanon, to be recognized as Palestinian nationals of a legitimate Palestinian nation entails acceptance of the OPTs as that future state.
} 
and an understanding of a distant homeland. ${ }^{14}$ But, it is not only the multiplication of media - satellite channels, the internet - that has resulted in greater coverage and the means for this young generation to supplement the information they have on their homeland, or enjoy greater avenues to remain connected to and imagine Palestine, it is also that the OPTs, the Palestinian-Israeli conflict, and the failed peace talks, have been the focus of increasing news coverage, particularly by the pan-Arab news channels.

Since my research, an increasing number of young Palestinians have become more active on social media, including Facebook and Twitter, among others. These new media, and refugees' growing reliance on them to access stories and images not covered by the mainstream media, provide rich opportunities for further research and analysis.

\section{References}

Alterman, J. (1998) New Media New Politics? From Satellite Television to the Internet in the Arab World. Washington DC: Washington Institute for Near East Policy.

Anderson, B. (1991) Imagined Communities. London and New York: Verso.

Appadurai, A. (1996) Modernity at Large: Cultural Dimensions of Globalization. Minneapolis and London: University of Minnesota Press.

(1991) 'Global Ethnospaces: Notes and Queries for a Transnational Anthropology', in R. Fox (ed), Recapturing Anthropology, Sante Fe: School of American Research Press

Economy', Theory, Culture \& Society, Vol. 7, No. 2, June, 295-310

Aouragh, M. (2011) 'Confined Offline - Traversing Online: Palestinian Mobility through the Prism of the Internet', Mobilities, Vol. 6, No. 3, 375-397

(2010) Palestine online: transnationalism, the internet and the construction of identity. London: I.B. Taurus.

(2008) 'Everyday resistance on the internet: the Palestinian context', Journal of Arab and Muslim Media Research. Vol. 1, No. 2, 109-130

Couldry, N. and A. McCarthy (2004) 'Orientations: mapping MediaSpace', in N. Couldry and A. McCarthy (eds), Mediaspace: Place, Scale and culture in a media age, London and New York: Routledge.

\footnotetext{
${ }^{14}$ Until recently, very little ethnographic research on media use in the Arab world has been undertaken. For an exception, see in particular Aouragh, 2013, 2010, 2008; and Alexander and Aouragh, 2014. Also, for recent work on the role of new media in the Arab world, see Ghannam, 2011; Gunter and Dickinson, 2013; Kallander, 2013; Kraidy, 2012; and Salamandra, 2005, 2008.
} 
Dajani, N. (1992) Disoriented Media in a Fragmented Society: The Lebanese Experience, Beirut: American University of Beirut.

Dorai, M.K. (2002) 'The meaning of homeland for the Palestinian diaspora:

Revival and transformation', in N. Al-Ali and K. Koser (eds), New Approaches to Migration? Transnational communities and the transformation of home, London: Routledge.

Feldman, I. (2006) 'Home as a Refrain: Remembering and Living Displacement in Gaza', History and Memory. Vol. 18, No. 2, Fall/Winter, 1047

Gupta, A. and J. Ferguson (1997) 'Culture, Power, Place: Ethnography at the End of an Era', in A. Gupta and J. Ferguson (eds), Culture, Power, Place: Explorations in Critical Anthropology, Durham and London: Duke University Press.

Jamal, A. (2007) 'Media culture as counter-hegemonic strategy: the communicative action of the Arab minority in Israel", Media, Culture \& Society, Vol. 31 (4), 559-577

Jensen, K. (2002) 'The qualitative research process', in K. Jensen (ed), A Handbook of Media and Communication Research: Qualitative and quantitative methodologies. London and New York: Routledge.

. (1998) 'Introduction', in K. Jensen (ed), News of the World: World Cultures look at television news. London and New York: Routledge.

Karam, I. (2007) 'Satellite Television: A Breathing Space for Arab Youth?', in N. Sakr (ed), Arab Media and Political Renewal: Community, Legitimacy and Public Life, London and New York: I.B. Tauris.

Kelly, J. (2004) Borrowed Identities. New York: Peter Lang Publishing, Inc.

Kraidy, M. M. and J. F. Khalil (2009) Arab Television Industries. London: Palgrave MacMillan.

Morley, D. (2000) Home Territories: Media, Mobility and Identity. London and New York: Routledge.

Morley, D. and K. Robins (1995) Spaces of Identity: Global Media, Electronic Landscapes and Cultural Boundaries. London and New York: Routledge.

Naficy, H. (1993) The Making of Exile Cultures: Iranian Television in Los Angeles. Minneapolis, London: University of Minnesota Press.

Patton, M.Q. (2002) Qualitative Research \& Evaluation Methods (3 ${ }^{\text {rd }}$ edition). Thousand Oaks, CA: Sage Publications. 
Peteet, J. (1995) 'Transforming Trust: Dispossession and Empowerment among Palestinian Refugees', in E. Daniel and J. Knudsen (eds) Mistrusting Refugees, Berkeley and Los Angeles: University of California Press.

Sakr, N. (2007) Arab Television Today. London and New York: I.B. Tauris.

Sayigh, R. (1979) The Palestinians: From Peasants to Revolutionaries. London and New York: Zed Books.

Shohat, E. and R. Stam (1994) Unthinking Eurocentrism: Multiculturalism and the media. London and New York: Routledge.

Young, J. (1997) 'Toward a Received History of the Holocaust', History and Theory. Vol. 36, No. 4, December, 21-43

May Farah received her PhD from the Department of Media, Culture and Communication at New York University and is currently an assistant professor of Media Studies in the Department of Sociology, Anthropology, and Media Studies. Her primary research interest focuses on the relationship between diasporic populations and national identity in a globalized media age. More broadly, she is also interested in issues of mediated nationalism and representations, transnationalism and spatiality, and new media. Her work is situated at the intersections of Media Studies, Cultural Studies, and Middle Eastern Studies with a particular emphasis on theories of diaspora, nationalism, and the transnational and global media. 